\title{
Demographic differences in hiker cellular technology use in backcountry areas in Montana's Custer Gallatin National Forest
}

\author{
Alexandra Miller \\ Eastern Kentucky University \\ James N. Maples \\ Eastern Kentucky University \\ Michael J. Bradley \\ Arkansas Tech University
}

\begin{abstract}
Technology remains an important part of outdoor recreation, ranging from the introduction of lighter materials in gear to new gadgets that improve the outdoor experience. Recently, advances in cellular technology and mobile devices have presented new opportunities for using mobile technology in backcountry areas. Applications ranging from public lands apps to GPS apps are a now a common find in outdoor recreation areas. Use of mobile technologies, such as cellular phones, can differ by demographic variables such as sex, age, and income. This presents a valuable opportunity to explore how and why demographics may shape the use of cellular devices while in the backcountry. This study examines technology use among hikers in Montana's Custer Gallatin National Forest. Using data from an online survey, the researchers explored the importance of eight different uses of cellular technology while in the backcountry and analyzed how these responses vary by sex, age, income, and education categories. The results indicate cellular technology plays a varied, albeit often neutral or even unimportant, role in backcountry outdoor recreation situations. Notably, these experiences do vary by age, education, and income categories but, surprisingly, not sex. Important outcomes include new understanding of hiker use of cellular devices as cameras, wayfinding devices, and for information gathering while in the backcountry.
\end{abstract}

Keywords: Hiking; technology; cellular devices; demographic differences; wayfinding; techscape

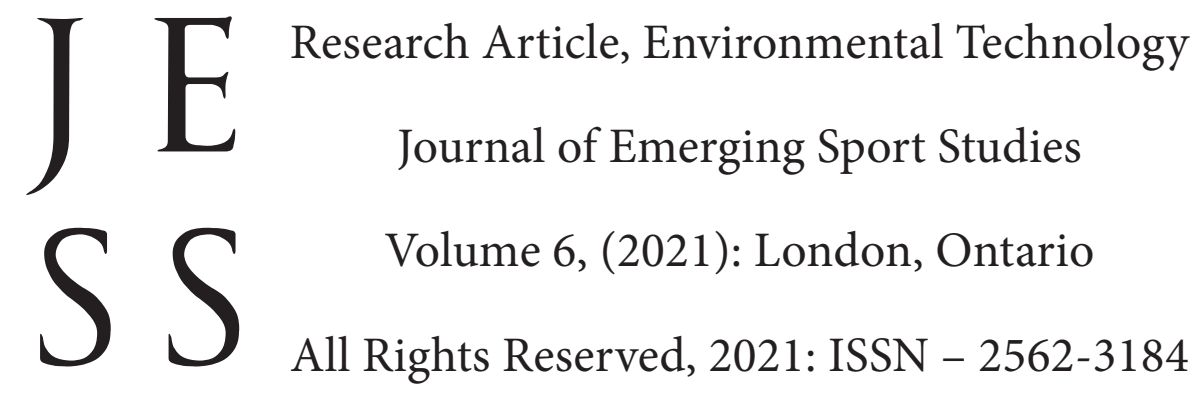


Journal of Emerging Sport Studies - Miller, Maples, \& Bradley “Demographic Differences...”

\section{Introduction}

$\mathrm{T}$

lechnological advancements are an important part of outdoor recreation, whether considering improvements in gear or access to new techniques or information for experiencing outdoor recreation areas (Subramanian, Noel, and Paquin 2020; Bolliger \& Shepherd, 2017). Mobile technology (such as the cellular phone) has now integrated into how outdoor recreation users actively engage in outdoor spaces (Dustin et al, 2017; Janssen et al, 2017). Increasingly, land managers also now engage outdoor recreation users through technological advances, such as the creation of public land cellular apps, thus increasingly blurring the expansive reach of mobile technology (Martin, 2017).

Researchers argue mobile technology has inadvertently interrupted or impinged upon outdoor recreation user experiences (Martin, 2017; Zuckerman, 2013; Shultis, 2012). The prevalence of mobile technology has creat- ed a conundrum among outdoor recreation users: can the outdoors now be experienced without the use of mobile technology? Mobile technology offers new opportunities for outdoor recreation users to bring this technology into the backcountry, as it can sometimes be used independent of cellular networks while in the backcountry. This blurry area between civilization and a wilderness experience has been compromised by a theoretical zone known as the techscape (Moor, 2016).

This "techscape" represents the rapidly increasing, extensive reach of mobile technologies (such as cellu- lar devices) into areas where no such technology exists (Martin, 2017; Moor, 2016). Extensive research indicates technology (particularly cellular phone and communication technology use) may detract, limit, or alter the ex- periences offered in the backcountry by redirecting a visitor's attention from the areas around them to a mobile device (Martin, 2017; Zuckerman, 2013; Shultis, 2012; Borrie, 2000; Ewert \& Shultis, 1999). As such, mobile technology is particularly poised to change how outdoor recreation users experience the outdoors going forward. Recent work (Clark et al, 2020; Sharp et al, 2018) has found outdoor recreation experiences and knowledge may vary by common demographics such as sex, age, education, and income. Additional research has similarly found differences in how different demographics use technology in varied ways (Kavčič, 2019; Pan- chanadeswaran et al, 2019; Colombo et al, 2018). This creates an important gap in the literature where research is needed to explore how mobile technology is engaged similarly or differently across these demographic categories. Moreover, this provides an opportunity to examine how a singular device, the cellular phone, might be used for different purposes in the backcountry based on demographics.

In this study, the researchers explore cellular technology use among hikers in the backcountry. Using a convenience sample of hikers in Montana's Custer Gallatin National Forest, this study examined how four de- mographic variables (sex, age, education, and income) may shape how and why technology is used while hiking in the backcountry across eight uses of mobile technology. Findings indicate, overall, hikers place low importance on using technology while in the backcountry. That stated, difference of means testing indicates these mean responses vary in several cases by age, income, and education but, inexplicably, not sex. Looking forward, the findings of this study present new opportunities for future research in examining mobile technology use in the backcountry. It also further informs marketing approaches to technology and potential land management uses as society reconsiders how technology can enhance (or detract) from our experiences in the outdoors, while also offering an opportunity to understand how different demographics might engage public lands. 


\section{Literature Review}

Rapid improvements made in technology within the last decade have expanded into various fields and activities. One much debated area of that technology use is outdoor recreation. The technology being used includes smart-phones, iPads, global positioning system (GPS), radios, geographic information systems (GIS), digital cameras, and satellite phones (Bolliger \& Shepherd, 2017). Technology has also created new potential for extending the boundaries of what is possible in sports, ranging from digitalized tennis rackets to precise measures of judge's courtside decisions (Subramanian, Noel, \& Paquin, 2020; Collins \& Evans, 2011). An aspect of mobile technology that has become more popular is apps where users can access real time trail information about water sources and campsites (Martin, 2017). Park apps offer access to maps of the park and other park information, such as information on native plants found in the region, policies (e.g. camping restrictions), and historical data.

Demographics of those using technology in the outdoors varies. Bolliger and Shepherd's (2017) study on technology use in outdoor education programs indicated their sample contained participants whose ages ranged from 22 to 94 years old. Dustin and associates' (2017) discussion of the Pacific Coast Trail (PCT) indicated most hikers are in their 20s and 30s and often come from urban places, while Weatherby and Vidon (2018) and Howard and Goldenberg (2020) note female hikers using mobile technology and social media as a form of empowerment on the PCT. Similarly, Janssen and associates (2017) found notable differences in how runners utilize mobile applications and sports watches. There, apps were often used by novice runners and younger runners, while sports watches were the domain of older, more experienced runners. The end result is a largely diverse population approaching technology use in outdoor recreation areas from myriad backgrounds, ideas, and experiences.

Research supports that technology use, particularly mobile technology use, can vary by demographic, even beyond outdoor recreation. For example, Panchanadeswaran and associates (2019) found that female sex workers used mobile devices as a central tool for social connectedness to clients and within their working community, as well. Columbo and associates (2018) examined how grandmothers utilized mobile technology to connect with their grandchildren, finding that generational differences emerge in how mobile technology is applied. Moreover, their study reported a sense of appropriateness among each generation in the correct way to use technology. Similarly, Kavčič and associates (2019) reported problematic social media uses (such as catfishing) were negatively correlated with age. Moreover, they found differences by sex in use of mobile phones, with findings indicating females more often overusing cellular devices and engaging in online "creeping."

Demographic differences in technology use overlaps with a common issue in outdoor recreation research: demographics, diversity, and inclusiveness in public lands. Importantly, public areas offer a valuable location for persons from all backgrounds to engage in a shared space (Low, Taplin, \& Scheld, 2009). Recent work indicates certain groups experience barriers that prevent them from interacting with public lands in certain ways. For example, McCreary and associates (2018) identified that persons and families with lower incomes are less apt to spend the costs of transportation to visit public lands, while persons with advanced age or certain disabilities have difficulty accessing certain sites (Corazon et al 2019; Williams et al, 2004). Age is 
particularly problematic, in that outdoor recreation has long been socialized as an activity belonging to older (and typically, white) males (Scott \& Lee, 2018;Vaske \& Lyon, 2014). Learning more about technology use patterns based on groups with differing levels of access and inclusivity, then, could offer insight for public land managers seeking to include these groups by providing more data on how these groups utilize public lands.

Technology can mediate how users interact and understand their environment. Thompson and associates' (2013) study showed pedestrians who were distracted by their phones failed to perform routine safety behaviors before they stepped out into the street. Similarly to the pedestrians observed, researchers argue hikers have, arguably, also become increasingly distracted by their mobile devices and have become out of touch with their environment (Dustin, Amerson, Rose, \& Lepp, 2019; Dustin et al., 2017). In a study of North Carolina's Outward Bound programs, participants who did not have knowledge of the instructor's satellite phone had a greater feeling of oneness than the participants who knew about the satellite phone (Holden, 2004). The study also found that the more the phone was present (physically and hypothetically) the greater the impact was on the participants' experiences. Building upon this finding, researchers have repeatedly found that bringing technology into the outdoors potentially detracts from the outdoor experience in varied ways by changing the user's focus and purpose for being outdoors (Martin, 2017; Zuckerman, 2013; Shultis, 2012; Borrie, 2000; Ewert \& Shultis, 1999). Likewise, technology can play roles in shaping one's connection and attachment to places (Amerson, Rose, Lepp, \& Dustin 2020; Trentelman, 2009). This is something that could include (as in Amerson et al., 2020) place attachment to outdoor recreation areas.

Recent work also indicates technology is altering how outdoor recreation users satisfy specific needs through technology. Use and Gratification theory posits that users select technology to meet specific needs. Dustin and associates (2017) note that today's Pacific Coast Trail hikers envision the trail as a social experience, which includes phone messaging to keep connected with other hikers or using YouTube video logs of the experience to connect with those not on the trail. This also includes support and empowerment for women hiking the trail (Howard \& Goldenberg, 2020; Weatherby \& Vidon, 2018). This provides evidence supporting the Uses and Gratification theory, as users adapt technology to fulfill the social portion of an otherwise frequently solitary hiking experience (Ahad \& Anshari, 2017; Leung \& Wei, 2000).

There is an ongoing theoretical argument that there should be a distinct line between the tech world and the outdoors; the belief is that too much technology ruins the experience the outdoors gives to people (Shultis, 2012). Moor (2016) defined a clear techscape boundary between developed areas and undeveloped wilderness areas. There is a belief that some places should remain "tech free" but some places could benefit from the added technology (Martin, 2017; Zuckerman, 2013), while others have noted the fluid nature of changing technology and its role in everyday life is subject to reinterpretation (Borrie, 2000; Ewert \& Shultis, 1999).

Park management professionals and researchers have increasing concerns about communication and information technology use. One prevalent concern is that the advancement of technology supports inexperienced people putting themselves into backcountry scenarios with reduced concern for safety or awareness of when one is in danger (Martin, 2017). One common concern is phones are now a safety net, rather than commonsense or training, although no research has correlated technology with a need for rescue. Moreover, the flip side of this is technology may actually improve rescue odds. Nevertheless, depending solely on mobile technology 
for access to things like maps or orientation does pose an issue for any outdoor recreation user, regardless of experience level. Fewer people are learning how to use a map and compass and relying solely on their cellular device and/or satellite GPS; because of this, more inexperienced hikers have ended up lost or off trail (Martin \& Pope, 2012).

Land managers are also coping with the costs of additional maintenance, as more people journey into backcountry spaces with the support of technology. On the positive, this means more people can experience back- packing and other forms of outdoor recreation, but also translates into more boots on the trail, which means more work to stabilize trails (Cole, 2004; Wilson \& Seney, 1994). More traffic results in more damage to the surrounding wilderness, due to trampling, wherein plants and vegetation can die and the soil will become compacted (Cole, 2004) and more widespread impacts result from the rec- reational activities that tourists engage in. For ecotourists engaged in adventurous pursuits, hiking and camping are perhaps the most common activities that can have profound ecological impacts. This is particularly true in more remote places, protected as parks or wilderness. Of the many environmental effects of hiking and camping, impacts on soil and vegetation have been most thoroughly explored. Consequently, the literature on this subject is voluminous and is a challenge to thoroughly review. This added traffic is not just from hikers; with horseback riders and motor vehicle traffic increases, many parks are unable to keep up with trail maintenance and the immense traffic they are experiencing (Wilson \& Seney, 1994).

This leaves mobile technology at an intricate, complicated precipice. It is something that is likely progressively changing how one understands outdoor recreation, as technology becomes increasingly commonplace in the backcountry. It has become a tool for engaging outdoor areas and a means for sharing the experience with others. Land managers have often embraced this change, even as it means increased trail use costs through higher visitation, and ostensibly more calls for assistance as the barrier to backcountry spaces is winnowed by mobile technology. One certainty is that mobile technology will not be leaving the backcountry anytime soon. The techscape has now permeated most areas of the nation, including outdoor recreation areas, such that even the idea of wilderness is, in many instances, an evasive experience. What remains now, then, is to learn more about usage patterns, understand more clearly how technology is being used, particularly mobile technology, in outdoor recreation areas, and to explore how use may vary by demographic variables. If technology is effectively here to stay, it behooves all parties interested in the backcountry to have a clearer understanding.

\section{Methods}

In this study, the researchers explored how technology, specifically mobile technology, is used in the backcountry and seek to understand how various demographic categories might shape this use. Previous studies, such as Clark and associates (2020) and Sharp and associates (2018), indicate outdoor recreation experiences may slightly vary based on demographics. In both papers, outdoor recreation users' awareness of minimal impact behaviors varied by their income. In other studies, demographic variables similarly shaped how users experienced outdoor recreation opportunities (Flores \& Kuhn, 2018; Sage et al., 2018). As such, this 
paper builds on this literature by exploring if technology use in at least one hiking area might vary by sex, by age, by education, and/or by income. These questions are addressed using examination of descriptive means, which are statistically examined for differences of means.

The researchers specifically examined mobile technology use among hikers in the Custer Gallatin National Forest (CGNF) and how use may vary across certain demographics. The measure includes eight items, examining the importance of using mobile technologies while in the backcountry. These include to use mobile technology to keep in contact with family/ friends, to use a phone as a camera, to capture and share moments online, to feel safe, to use GPS/maps, to get information about local places, to find local businesses, and to find one's way around. Respondents were asked to rank the importance of each item (where 1 equals not at all important and 5 equals very important) in terms of the respondents' technology use in the backcountry. The survey also included demographic measures of sex, age, income, and education. These variables, measured using common categories followed in previous research (such as Sharp and associates, 2018), were recoded as dichotomous categories for analysis using testing. As such, this paper examines how mean responses may vary based on being in certain demographics. ${ }^{1}$

Data for this paper were collected in an online survey of hikers visiting the CGNF in 2018 as part of an economic impact study done in the region (Maples \& Bradley, 2018). In all, 537 persons participated in the study, with 113 of those respondents electing to take an additional survey on technology use among hikers. In all, 111 of the 113 completed the additional technology survey examined in the current study. As there are no known statistics on how many persons would be in the CGNF hiking population, this should be treated as a convenience sample.

\section{Analysis}

Table 1 lists the descriptive statistics of the sample. Overall, respondents were mostly male (65\%). Ages range across three categories (18-30, 31-50, and 51 and above) and are more concentrated in the latter two catego- ries. Income is distributed fairly evenly across four categories $(\$ 0-\$ 29,999, \$ 30,000-\$ 49,999, \$ 50,000-\$ 74,999$, $\$ 75,000$ and up). The largest category (at $28 \%$ ) is in the $\$ 75 \mathrm{~K}$ and up category, which is a common finding in other studies on outdoor recreation. Education is separated into three categories (less than BA/BS degree, BA/ $\mathrm{BS}$ degree, greater than BA/BS degree), with the bulk of respondents having a BA/BS degree or higher.

Table 1 also describes the eight technology measures used in this study and their means. In this measure, a higher score indicates higher importance for that use of technology. Overall, cellular technology's importance was largely neutral to low importance. For example, hikers placed low importance on using mobile technology to stay connected to friends/family (mean $=2.12$ ), capture important moments and share them online $(2.14)$, or find local businesses the respondent might want to visit (2.16). In fact, only one variable fully fell in the neutral category: using a phone as a camera (3.77). As such, this initial univariate analysis indicates that hikers may place a low importance overall on technology use in the CGNF.

Table 2 shows a test analysis of means by demographic categories. The table reports the mean responses for each demographic category and includes significance. In all, eleven categories indicated statistically 
different mean responses to the Likert items. Age proved significant in four of these instances. Average importance in using a cellular phone as a camera varied in two age groups: persons aged 31-50 and persons aged 51 and up. Persons aged 31-50 indicated higher importance in using a phone as a camera, while persons aged 51 and up showed less importance. Using cellular devices to find local businesses to visit also varied for persons in the 18-30 and 31-50 ranges. Income varied on five cases. Persons in the lowest income bracket $(\$ 0-\$ 29,999)$ scored lower than the overall mean, while persons in the $\$ 30,000-\$ 49,999$ scored higher when asked about using phones as cameras. Persons in the highest income bracket $(\$ 75,000$ and higher) scored higher than the overall mean when asked about using their device as a GPS or to get information about places to visit. Likewise, income informed using phone to find one's way around, with the lowest income bracket scoring lower than the overall mean and the highest income bracket scoring higher. Education proved statistically different in one case. Persons with less than a four-year degree scored higher than the mean regarding use of their device for GPS or mapping apps.

\section{Discussion, Limitations, and Conclusions}

The results of this study offer several useful discussion points. First and foremost, the bulk of the technology variable support the idea that hikers may be thinking about the techscape division between the front and backcountry areas, despite recent efforts to extend cellular networks in the Custer Gallatin National Forest. Respondents dis- agreed overall on seven of eight items. Only one (using a phone as a camera) had a neutral to lukewarm positive response. One difference here may be the use of a cellular device (and their ever-increasingly high-performance cameras), which offer a convenient, low-cost, and lightweight alternative to cameras. They do not require connec- tion with networks, unlike the other seven items. In comparison, staying connected to friends and family had the lowest mean responses (2.12), indicating that users may truly be seeing the outdoors as a break between front and backcountries. Using devices to find local businesses to visit (mean of 2.16) may indicate a desire to be separate from interacting with others (almost certainly in the frontcountry) during their visit. These findings somewhat support the idea again that hikers in the area studied are making a distinction between where they choose to use cellular devices.

Although phones may not be part of keeping in touch, the findings show phones are still part of photographically documenting one's journey in the backcountry, and the differences by demographic are decidedly peculiar. In all, four t-tests proved significantly different mean responses when asked about using one's phone as a camera. In age, persons 31-50 had a significant $(\mathrm{p}=.05)$ higher mean response, while persons 51 and above had a significant $(\mathrm{p}=.01)$ decrease in response. This is an interesting finding, indicating persons over 50 are perhaps less apt to envision their phone as a camera when in the backcountry, whereas younger generations have long used cellular devices as cameras and see this as a normal behavior. This ostensibly could be because this age group ex- perienced a period in which cameras were treated as a separate device, while those in the 31-50 age bracket grew up with cellular technology (particularly those on the younger end of the age bracket).

Additional findings regarding income also contribute to this puzzle. Persons in the lowest two income categories had significant lower means (both at $\mathrm{p}=.05$ ) in their use of phones as cameras. This is perhaps a 
counterintuitive finding, given that persons with more income would have potentially more access to camera equip- ment and higher quality camera phones. It could also be that the users do not feel taking a picture was particularly important. One shortcoming of this question is that portable action cameras (such as the Go-Pro series) are largely available to any income category. As such, this could shape this finding. Another option deserving more research is whether or not an individual's income might determine one's interest in using phones to take pictures, or if having less access to newer phones (with better higher picture quality) somehow shapes this relationship.

While hikers may be using phones to take pictures in the backcountry, it likely was not for the purpose of being able to share those pictures with others. It was found that using a phone to capture important moments and share them online was overall not important to hikers. This finding showed no significance or marginal significance. This was perhaps surprising, considering the previous finding of hikers using cellular devices to document their journey. One possible explanation could be that hikers are not sharing the pictures right away, choosing to upload them later, perhaps after applying filters or edits to the pictures and sorting through the best pictures with- out draining their battery or delaying their trip. Likewise, using the phone outside of airplane mode, which pauses attempts to connect to networks, would extend battery life between charges. This use pattern certainly deserves more research to fully understand its rationale.

Interestingly, and perhaps desirably, there was no mean difference in the importance of using a phone to feel safe across all demographics, despite parts of the Custer Gallatin National Forest being quite remote. One group was marginally different ( $\mathrm{p}>.05)$ : the lowest income category was marginally lower in importance. This finding is not entirely surprising. Phones are not a reliable form of safety in the backcountry and getting a signal may involve walking miles further along the trail. From a Forest Service perspective, it is potentially desirable that users are not envisioning their phones as important safety devices, instead choosing to be more self-reliant. Moreover, other technology, such as spot beacons, and informed safety practices like hiking in groups and leaving a detailed hike plan help remedy the use of phones for safety purposes. This finding also dips into social justice research on access to outdoor recreation and dispels the idea that female hikers felt a greater need to have a phone available for safety purposes. Instead, we find that all hikers in this sample are responding more or less the same in terms of the importance of having a phone in the backcountry for safety purposes.

Researchers found Using cellular devices for GPS and mapping present two potentially odd but significant relationships. One relationship is that hikers with slightly higher incomes placed a higher importance on using phones as GPS devices. People with higher incomes could afford to purchase more expensive and higher tech phones that can potentially give them the ability to use their phone to navigate the backcountry. This could also relate to the ability to travel to new locations due to having more disposable income and needing GPS to find one's way in that new area. Next, persons with less education had a higher mean importance on using cellular devices for GPS purposes. One explanation here could link back to resources. For example, those with more resources and higher incomes tend to be older, something recently amplified by income and opportunity differences between younger and older age groups. Another explanation could be differences in how different age groups, who often have different income categories, use park/trail apps on phones to navigate the backcountry versus the use of maps and compasses. One potential shortcoming with this question 
could also be that official Forest Service trails would be relatively well-signed and clear, meaning it could be possible, even if undesirable, to navigate with no map.

Hikers using their technology to get information about places they are visiting had one obvious relationship: people with higher incomes had slightly higher mean responses of technology use. It is conjecture, but people with higher incomes may have more disposable funds for spending and this might explain the difference. Age had a similar result here, the older age group (age 31-50) had slightly lower mean responses than the overall group.

Meanwhile, the younger age group (age 18-30) showed slightly higher mean responses. This could relate to the use of apps and socialization. For example, the younger age group could be more likely to turn to things like online reviews to gain knowledge of other people's opinions and experiences because they have effectively lived their entire lives with some level of cellular access to these services. This socialization may also carry over into different cellular device use patterns while in the backcountry.

This study has offered several ideas for further research built around the study's limitations. This study represents only one part of the hiking community, hikers found in the Custer Gallatin, and researchers should take care when applying the results to other communities. There also could be some bias in certain respondents being involved in the email lists used as part of the convenience sample. As a result, future projects should include larger sample sizes and potentially even various geographic locations. This may allow a better opportunity to investigate and understand how different age groups use technology based on their use patterns in the frontcountry.

The study also focuses on only one category of outdoor recreation activity, hikers, and may not apply to other groups, such as climbers or mountain bikers. As such, further research should also investigate a wider array of outdoor recreation activities rather than focusing solely on hikers. Future studies may also include activities or even examine outdoor recreation users in a more general context. Other technology, such as health trackers or action cameras like GoPros, could provide more detail about use patterns.

This study also includes only eight motivations for cellular use. To expand on this study, interviews with outdoor recreation users could reveal additional reasons for using cellular devices in the backcountry, which could subsequently be analyzed. Likewise, there are those who simply choose to leave their cellular devices at home while enjoying the outdoors. More work should examine their motivations for leaving technology behind when crossing into the backcountry.

Another limitation for this study is the methodology of an online survey, a technology in and of itself. Thus, it is important to note persons not likely to utilize technology during their outdoor recreation experience may not be aware of such a study or may hesitate to participate in online survey research.

Technology use and technology in outdoor recreation has been an issue for quite some time, as is the idea that nature and outdoor recreation is an escape from technology and industry. Perhaps one of the most notable American naturalists, Henry David Thoreau, wrote of his time at Walden Pond to escape to, and reconnect with, nature. His writings from this time discussed the value of nature and the benefit to escaping society and reconnecting with the natural world. Other naturalists and philosophers followed, such as Ralph Waldo Emerson, John Muir, and more, and debated and discussed the idea of reconnecting with nature. One 
can easily make the claim that these musings were embedded in a feeling perhaps too disconnected today, due to the industry and technology of their respective ages. While industry and technology progressed, so did the idea of maintaining a connection with nature as technology and industry pulled individuals into urban settings and away from outdoor leisure and recreation. Significant shifts in technology through parks began with motorized vehicles and their ability to transport people to and within parks and refuges in the early-tomid-1900s. The trend certainly extended with the addition of recreational vehicles and technology that made it easier and more comfortable to camp and stay in nature for a few nights and longer. This includes technology of new clothing, food preparation, camping gear, and recreation gear for a wide array of activities. While challenges were certainly in place and outdoor recreation management struggled with more people outdoors and where and how to allow technology in parks, the advances have provided outdoor recreation experiences to many more people as they overcame barriers to engage in outdoor recreation.

However, cellular technology has certainly added a new chapter to the discussion of technology in outdoor recreation and in natural settings. As technology proliferated and became more accessible, so did the use of the technology in outdoor recreation. Utilizing technology for communication, safety, and wayfinding certainly makes sense, as does its use for interpretation and education. As more people engage in outdoor recreation, having technology to make engagement safer and educate the public about resources allows for technology to progress the idea that people should and need to reconnect with nature. Having a camera on a cellular device is nothing new, but the technology and advances in cameras have eliminated the need for people to carry a cellular phone and a digital camera. Hikers, birders, and more can now document their recreation endeavors while enjoying the great outdoors (Wang, et al., 2011). Geocaching, a popular outdoor recreation activity, witnessed a remarkable increase in popu- larity beginning in the early 2000 s, due to the availability of cellular devices accessing GPS satellites for location services. Beyond geocaching, location services offer new hope in safety for people engaging in a variety of outdoor recreation endeavors. Technology has certainly altered the outdoor recreation experience, and many have embraced these incursions into the outdoor recreation space (Peterson, et al., 2021).

Managers of natural areas might argue that the use of technology is beginning to change the idea of what it means to spend time in the outdoors (Shultis, 2012). The outdoor recreation experience, however, is a vehicle steered by the outdoor recreation user, and studies show that many are empowered by technology to feel safer and more comfortable in nature, due to technological advances (Shultis, 2015). Use of various applications on cellular devices continues to increase, as does the creation of these applications for specific events, programs, and experiences (da Mota \& Pickering, 2020). In 2021, nearly 85\% of Americans owned a smartphone. The age of the cellular device and technology is now and managers of outdoor recreation areas and programs certainly need to understand, and perhaps embrace, its use (Mobile fact sheet, 2021). While a debate on what a "true" or "pure" outdoor recreation experience is may continue (Martin, 2017), this research continues to provide information to make informed decisions regarding technology use for events and management of outdoor recreation, while also adding to the scholarship grappling with the idea of an outdoor recreation experience (da Mota \& Pickering, 2020).

The professional implications of technology use in outdoor recreation are much like the aforementioned 
debate on use of technology in outdoor recreation, meaning the professional use has room to mature and develop as use of technology progresses and device applications continue to progress. Technology continues to make nature more accessible in a variety of ways, as private developers of technology and applications monitor and respond to needs and preferences for technology use in outdoor recreation. Management of these areas and experiences should continue to monitor and respond as well and focus on increased awareness and understanding as technology continues to alter the future of how people use and access nature for recreation.

\section{Notes}

Although race was also included in the survey, race was excluded from the study because there were too few cases to conduct a meaningful analysis of the topic. This finding is in line with several studies indicating that outdoor recreation is not equally accessible to many minority groups. 


\section{References}

Amerson, K., Rose, J., Lepp, A., \& Dustin, D. (2020). Time on trail, smartphone use, and place attachment among Pacific Crest Trail thru-hikers. Journal of Leisure Research, 51(3), 308-324.

Bolliger, D. U., \& Shepherd, C. E. (2017). An investigation of mobile technologies and web 2.0 tools use in outdoor education programs. Journal of Outdoor Recreation, Education, and Leadership, 9(2), 181-196.

Borrie, W. T. (1998). Impacts of technology on the meaning of wilderness. In Personal, Societal, and Ecological Values of Wilderness: Sixth World Wilderness Congress Proceedings on Recreation, Management, and Allocation, 2, 87-88.

Clark, B.G., Maples, J.N., \& Sharp, R.L. (2020). Awareness and application of minimum impact practices among rock climbers in the Red River Gorge, Kentucky. Journal of Outdoor and Environmental Education.

Cole, D. N. (2004). Impacts of hiking and camping on soils and vegetation: a review. Environmental Impacts of Ecotourism, 41, 60.

Collins, H \& Evans R. (2011). Sport-decision aids and the "CSI-effect": Why cricket uses Hawk-Eye well and tennis uses it badly. Public Understanding of Science, 21(8), 904-921.

Colombo, F., Aroldi, P., \& Carlo, S. (2018). “I use it correctly!”: The use of ICTs among Italian grandmothers in a generational perspective. Human Technology 14(3), 343,365.

da Mota, V. T. \& Pickering, C. (2020). Using social media to assess nature-based tourism: Current research and future trends. Journal of Outdoor Recreation and Tourism, 30, 100295.

Dustin, D., Amerson, K., Rose, J., \& Lepp, A. (2019). The cognitive costs of distracted hiking. International Journal of Wilderness, 25(3), 12-21.

Dustin, D., Beck, L., \& Rose, J. (June 2017). Landscape to techscape metamorphosis along the Pacific Coast Trail. International Journal of Wilderness, 23(1), 25-30.

Flores, D. \& Kuhn, K. (2018). Latino Outdoors: Using storytelling and social media to increase diversity on public lands. Journal of Park and Recreation Administration 36(3), 47-62.

Hawes, M. (2017). Why wilderness should be remote. International Journal of Wilderness, 23(1), 38-41. Holden, T. (2004). The Impacts of satellite phone technology on a North Carolina Outward Bound School experience. Research in Outdoor Education, 7, 57-72.

Howard, I., \& Goldenberg, M. (2020). Women thru-hiker experiences on the Pacific Crest Trail: Gender influences, factors of success, and personal outcomes. Journal of Outdoor Recreation, Education, and Leadership, 12(1), 41-61.

Janssen, M., Scheerder, J., Thibault, E., Brombacher, A., \& Vos, S. (2017). Who uses running apps and sports watches? Determinants and consumer profiles of event runners' usage of running-related smartphone applications and sports watches. PLoS One (12(7), e0181167.

Kavčič, T., Levpušček, M.P., Zupančič, M., Poredoš, M., \&Bjornsen, C. (2019). Personal correlates of problematic types of social media and mobile phone use in emerging adults. Human Technology, 15(2), 256-278. 
Maples, J.N. \& Bradley, M. J. (2018). Economic impact of hiking in the Custer Gallatin National Forest Retrieved from https://static1.squarespace.com/static/54aabb14e4b01142027654ee/t/5bf31fbe03 2be432ef7ffee3/1542660031580/OA_CusterGallatinNF_HikingStudy2018.pdf

Martin, S. (2017). Real and potential influences of information technology on outdoor recreation and wilderness experiences and management. Journal of Park \& Recreation Administration, 35(1), 98-101.

Martin, S. R., \& Pope, K. (2012). The influence of hand-held information and communication technology on visitor perceptions of risk and risk-related behavior. In: Cole, David N., Wilderness visitor experiences: Progress in research and management; 2011 April 4-7; Missoula, MT. Proc. RMRS-P-66. Fort Collins, CO: US Department of Agriculture, Forest Service, Rocky Mountain Research Station 66, 119-126.

Mobile fact sheet. (2021, April 7). Pew Research Center, Washington, D.C. Retrieved from https://www. pewre- search.org/internet/fact-sheet/mobile/

Moor, R. (2016). On Trails: An Exploration. Simon \& Shuster: New York.

Panchanadeswaran, S., Unnithan, A.M., Chacko, S., Brazda, M., Wilson, N.B., \& Kuruppu, S. (2019). Female sex workers' use of mobile phones in India: Lessons in effective engagement. Human Technology, 15(1), 79-99.

Peterson, B. A., Fefer, J. P., Sharp, R. L., Brunson, M. M., \& Skibins, J. C. (2021). To connect or not connect: Vis- itor preferences for Wi-Fi and cellular network service at a national park. Social Sciences \& Humanities Open 4(1), https://doi.org/10.1016/j.ssaho.2021.100179.

Sage, J., Nicerson, N., Miller, Z.D., Ocanas, A. \& Thomsen, J. (2018). The complementary effect of national park fee increases on visitor spending in gateway communities. Tourism Review International 22(3-4), 187- 198.

Sharp, R., Maples, J.N., \& Gerlaugh, K. (2018). Factors influencing knowledge and self-reported application of leave no trace principles amongst rock climbers in Kentucky's Red River Gorge. Journal of Adventure Education and Outdoor Learning.

Shultis, J. (2012). The impact of technology on the wilderness experience: A review of common themes and ap- proaches in three bodies of literature. In: Cole, David N., Wilderness visitor experiences: Progress in research and management; 2011 April 4-7; Missoula, MT. Proc. RMRS-P-66. Fort Collins, CO: US De- partment of Agriculture, Forest Service, Rocky Mountain Research Station 66, 110-118.

Shultis, J. D. (2015). “Completely empowering”: A qualitative study of the impact of technology on the wilderness experience in New Zealand. In: Watson, Alan; Carver, Stephen; Krenova, Zdenka; McBride, Brooke, comps. Science and stewardship to protect and sustain wilderness values: Tenth World Wilderness Congress symposium; 2013, 4-10 October, Salamanca, Spain. Proceedings RMRS-P-74. Fort Collins, CO: US Department of Agriculture, Forest Service, Rocky Mountain Research Station $74,195-201$.

Shultis, J. (2001). Consuming nature: The uneasy relationship between technology, outdoor recreation and pro- tected areas. The George Wright Forum 18(1) 56-66.

Subramanian, V., Noel M., \& Paquin H. (2020). Tweet, set, match: negotiating the boundaries of digital technol-ogies in elite tennis. Science, Technology, and Society. 
Thompson, L. L., Rivara, F. P., Ayyagari, R. C., \& Ebel, B. E. (2013). Impact of social and technological distraction on pedestrian crossing behaviour: an observational study. Injury Prevention, 19(4), 232237.

Wang, D., Park, S., \& Fesenmaier, D.R. (2011). The role of smartphones in mediating the touristic experience. Journal of Travel Research, 51(4), 371-387.

Weatherby, T., \& Vidon, E. (2018). Delegitimizing wilderness as the man cave: The role of social media in female wilderness empowerment. Tourist Studies, 18(3), 332-352.

Wilson, J. P., \& Seney, J. P. (1994). Erosional impact of hikers, horses, motorcycles, and off-road bicycles on mountain trails in Montana. Mountain Research and Development, 77-88.

Zuckerman, L. (2013). America's national parks weigh solitude against cellular access. Retried from https:// www.reuters.com/article/usa-parks-cellphones/feature-americas-national-parks-weigh-solitudeagainst-cellu- lar-access-idUSL2N0AK10V20130119 


\begin{tabular}{|c|c|c|}
\hline Variable & $\mathbf{N}$ & $\begin{array}{l}\text { Per- } \\
\text { cent }\end{array}$ \\
\hline \multicolumn{3}{|l|}{ Sex } \\
\hline Male & 69 & 65.0 \\
\hline Female & 38 & 35.0 \\
\hline \multicolumn{3}{|l|}{ Age Categories } \\
\hline $18-30$ & 29 & 26.6 \\
\hline $31-50$ & 41 & 37.6 \\
\hline 51 and above & 39 & 35.8 \\
\hline \multicolumn{3}{|l|}{ Income Categories } \\
\hline$\$ 0-\$ 29,999$ & 26 & 26.0 \\
\hline$\$ 30,000-\$ 49,999$ & 26 & 26.0 \\
\hline$\$ 50,000-\$ 74,999$ & 20 & 20.0 \\
\hline$\$ 75,000$ and up & 28 & 28.0 \\
\hline \multicolumn{3}{|l|}{ Education Categories } \\
\hline Has less than BA/BS degree & 16 & 14.7 \\
\hline Has a BA/BS degree & 45 & 41.3 \\
\hline Has more than a BA/BS degree & 48 & 44.0 \\
\hline Variable & $\mathbf{N}$ & Mean \\
\hline \multicolumn{3}{|c|}{ Technology Variables (where $1=$ not at all important and $5=$ very important) } \\
\hline To stay connected to friends and/or family & & 2.12 \\
\hline To use my phone as a camera & & 3.77 \\
\hline To capture important moments and share them online & & 2.14 \\
\hline To feel safe & & 2.54 \\
\hline To use GPS and/or mapping apps & & 2.98 \\
\hline To get information about places I am visiting & & 2.52 \\
\hline To find local businesses I might want to visit & & 2.16 \\
\hline To find my way around the area & & 2.70 \\
\hline
\end{tabular}




\begin{tabular}{|c|c|c|c|c|}
\hline Variable & $\begin{array}{l}\text { To stay con- } \\
\text { nectedto friends } \\
\text { and/or family } \\
\text { (Mean: } 2.12 \text { ) }\end{array}$ & $\begin{array}{c}\text { To use my } \\
\text { phoneas a cam- } \\
\text { era } \\
\text { (Mean: } 3.77 \text { ) }\end{array}$ & $\begin{array}{l}\text { To capture important } \\
\text { moments \& share them } \\
\text { online (Mean: } 2.14 \text { ) }\end{array}$ & $\begin{array}{l}\text { To feel } \\
\text { safe(Mean: } \\
2.54)\end{array}$ \\
\hline \multicolumn{5}{|l|}{ Sex } \\
\hline Female & $2.10(1.226)$ & $3.90(1.34)$ & $2.16(1.25)$ & $2.68(1.45)$ \\
\hline Male & $2.19(1.15)$ & $3.57(1.28)$ & $2.05(1.31)$ & $2.34(1.47)$ \\
\hline \multicolumn{5}{|l|}{ Age Categories } \\
\hline $18-30$ & $2.28(1.36)$ & $3.93(1.28)$ & $2.03(1.23)$ & $2.83(1.46)$ \\
\hline $31-50$ & $1.98(1.037)$ & $4.10(1.13) \#^{*}$ & $2.20(1.18)$ & $2.37(1.44)$ \\
\hline 51 and above & $2.05(1.20)$ & $3.29(1.48) \# * *$ & $2.13(1.41)$ & $2.49(1.57)$ \\
\hline \multicolumn{5}{|l|}{ Income Categories } \\
\hline$\$ 0-\$ 29,999$ & $1.88(1.26)$ & $3.16(1.49)^{*}$ & $1.92(1.26)$ & $\begin{array}{c}2.15 \\
(1.22) \#^{\wedge}\end{array}$ \\
\hline$\$ 30,000-\$ 49,999$ & $2.31(1.19)$ & $4.23(1.03) \#^{*}$ & $2.42(1.27)$ & $2.73(1.40)$ \\
\hline$\$ 50,000-\$ 74,999$ & $1.75(.91) \#^{\wedge}$ & $3.70(1.30)$ & $2.15(1.34)$ & $2.55(1.76)$ \\
\hline$\$ 75,000$ and up & $2.50(1.29)^{\wedge}$ & $3.82(1.46)$ & $2.04(1.20)$ & $2.89(1.70) \#$ \\
\hline \multicolumn{5}{|l|}{ Education Categories } \\
\hline - BA/BS degree & $2.50(1.09)$ & $3.69(1.19)$ & $2.31(1.13)$ & $2.69(1.66)$ \\
\hline BA/BS degree & $2.05(1.31)$ & $3.80(1.40)$ & $2.11(1.33)$ & $2.47(1.42)$ \\
\hline \multirow[t]{2}{*}{$+\mathrm{BA} / \mathrm{BS}$ degree } & $1.98(1.08)$ & $3.77(1.35)$ & $2.08(1.28)$ & $2.54(1.52)$ \\
\hline & $\begin{array}{c}\text { To use GPS } \\
\text { and/or mapping } \\
\text { apps(Mean: } \\
\text { 2.98) }\end{array}$ & $\begin{array}{c}\text { To get infor- } \\
\text { ma- tion about } \\
\text { placesI am } \\
\text { visiting (Mean: } \\
2.52 \text { ) }\end{array}$ & $\begin{array}{l}\text { To find local businesses } \\
\text { Imight want to visit } \\
\text { (Mean: } 2.16 \text { ) }\end{array}$ & $\begin{array}{l}\text { To find my } \\
\text { way around } \\
\text { the area } \\
\text { (Mean: } 2.70 \text { ) }\end{array}$ \\
\hline \multicolumn{5}{|l|}{ Sex } \\
\hline Female & $2.90(1.47)$ & 2.43 (1.15)\# & $2.13(1.28)$ & $2.61(1.39)$ \\
\hline Male & $3.13(1.49)$ & $2.71(1.45) \#$ & $2.29(1.29)$ & $2.95(1.57)$ \\
\hline \multicolumn{5}{|l|}{ Age Categories } \\
\hline $18-30$ & $3.24(1.43)$ & $2.83(1.16)$ & $2.55(1.37)^{*}$ & $3.03(1.40)$ \\
\hline $31-50$ & $3.00(1.51)$ & $2.32(1.21)$ & $1.85(1.06) \#^{*}$ & $2.71(1.52)$ \\
\hline 51 and above & $2.77(1.44)$ & $2.49(1.35)$ & $2.15(1.32)$ & $2.44(1.42)$ \\
\hline \multicolumn{5}{|l|}{ Income Categories } \\
\hline$\$ 0-\$ 29,999$ & $2.69(1.40)$ & $2.19(1.20)$ & $1.85(1.12)$ & $2.23(1.21)^{*}$ \\
\hline$\$ 30,000-\$ 49,999$ & $2.77(1.45)$ & $2.54(1.10)$ & $2.46(1.20)$ & $2.81(1.44)$ \\
\hline$\$ 50,000-\$ 74,999$ & $2.85(1.63)$ & $2.20(1.10)$ & $1.75(1.33)$ & $2.81(1.48)$ \\
\hline$\$ 75,000$ and up & $3.54(1.42)^{*}$ & $3.07(1.41)^{* *}$ & 2.54 (1.55)\# & $3.36(1.59)^{*}$ \\
\hline \multicolumn{5}{|l|}{ Education Categories } \\
\hline - BA/BS degree & $3.69(1.44)^{*}$ & $2.62(1.20)$ & $2.25(1.18)$ & $3.25(1.57)$ \\
\hline
\end{tabular}


Journal of Emerging Sport Studies - Miller, Maples, \& Bradley “Demographic Differences..."

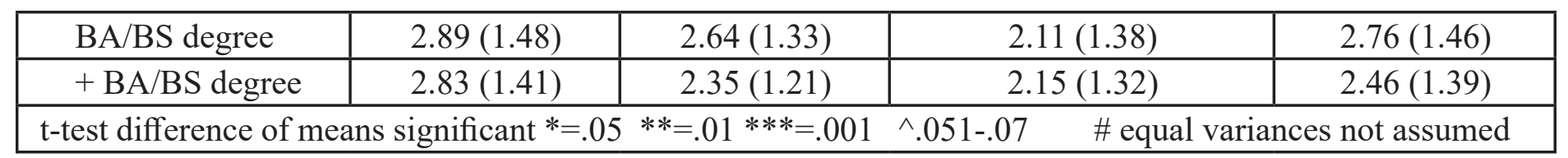

